\title{
On the Work-integrated Talent Training Mode of Computer Majors in Vocational Colleges
}

\author{
Hong Zhou \\ Department of Information Engineering,Hunan Radio and TV University,Changsha, Hunan, China \\ Email:9899213@qq.com
}

\begin{abstract}
Since the development of computer requires highskilled talents, computer major should combine professional training requirements with relevant vocational standards. A talent training mode---work-integrated learning which advocates "school-enterprise cooperation, integrated working and learning and simultaneous development of qualities and skills" are constructed in curriculum development. Furthermore, a "modularized, combined and advanced" professional curriculum system are constructed to explore and practice enterprise classroom pattern
\end{abstract}

Keywords- vocational college; work-integrated learning; talent trainings

\section{INTRODUCTION}

It is highlighted in the State Council's Decision on Energetically Developing Vocational Education that workintegrated learning system should be energetically promoted and work-integrated training mode should be considered as the key entry point ${ }^{[1]}$. Nowadays, "work-integrated learning" has even become the focus ${ }^{[2]}$ of the development thoughts of our vocational education during the "Twelfth Five-Year Plan".

At present, the majority of domestic vocational colleges lack enough cognition of work-integrated learning, which causes students' failure in training their comprehensive skills and reaching the requirements of high-quality skilled talents. How to construct a corresponding operating system and long-term mechanism of school-enterprise cooperation has become the consensus in vocational education by the Ministry of Education, relevant leading department of the industry and labor security department.

\section{II .THE PHILOSOPHY AND CONNOTATION OF WORK- INTEGRATED TALENT TRAINING MODE}

\section{A. Carry Out the Philosophy of Work-integrated Learning Mode}

Work-integrated learning is a talent training mode which integrates work with learning. In essence, its characteristic is to realize the integration of education and practice and school and society by integrating work with learning, so as to improve the quality of education. The implementation of work-integrated training mode must take the philosophies of vocational education as the guidance. Firstly, the philosophies of service, talent and brand must be established. Only by transforming the school-centered one-way thinking mode and setting up social demand-centered philosophy can cooperation be sought from employers. Only by establishing the philosophy that everybody can be a talent can students be taught in accordance with their aptitude and the traditional training mode be reformed; only by establishing brand philosophy can innovative development in vocational education mode in advanced countries be referred to form an independent educating brand ${ }^{[3]}$.

\section{B. The Connotation of Work-integrated Learning Mode}

Work-integrated learning is a talent training mode which aims at improving students' professional qualities and skills $^{[4]}$. Thanks to work-integrated learning, students can integrate theoretical study in classroom with practical work, which can not only enrich their knowledge but also exercise their abilities and achieve "three integrations". "Integration of deed and learning"---take practical work in the real society as an important constituent part of teaching to dynamically integrate deed with learning, and concurrently, "work" and "learning" also become the content regulated by vocation education teaching plans; "integration of the identity of student and employee"---transform the traditional simulated demonstrative internship into what enables students to be engaged in production and service on regular position as an employee and undertake corresponding responsibilities and obligations of the position in real production and service field; "integration of position and classroom"---break through the traditional closed teaching organizational form which centralized on school and classroom, and really integrate working with learning, so that students can learn on positions and work in an academic environment ${ }^{[5]}$.

As the philosophy and ideology of modern vocational education, work-integrated learning highlights that students' learning process must be closed combined with their practical work. The objective is to become vocation-oriented, dynamically integrate classroom teaching-centered school education and off-campus work through which students can obtain practical experience directly. It places an emphasis on inspiring and training students' manual, operating and skillmastering abilities, and reflects an open education and teaching philosophy under the conditions of market-oriented economy. 


\section{THE IMPLEMENTATION OF WORK-INTEGRATED AND SCHOOL-ENTERPRISE COOPERATION TRAINING MODE}

In recent years, the computer major in our school has been exploring to exert the role of enterprises by cooperating with different enterprises in running schools.

- Design teaching plans in accordance with the guidance that advocates "school-enterprise cooperation, integrated working and learning and simultaneous development of qualities and skills". Taking the computer major as the entry point, our school keeps a close touch with relevant enterprises when formulating talent training plans, extensively and profoundly investigates responsible persons,
HR supervisors, workshop directors, technical backbones and skillful craftsmen, and fully hears from industrial experts. Our school has successively implemented "ordertraining" and drawn up teaching plans with CITIC, Great Wall Broadband, Aipu Network, CHINALCO, MAIWEI Information, etc.

- Integrate working with learning in curriculum system, and take Computer Network major as the entry point, select and combine the learning process as the advancing ability mode shown in Fig 1 "basic module $\rightarrow$ small and medium network module $\rightarrow$ intermediate and advanced network module" in accordance with the working process of professional positions.

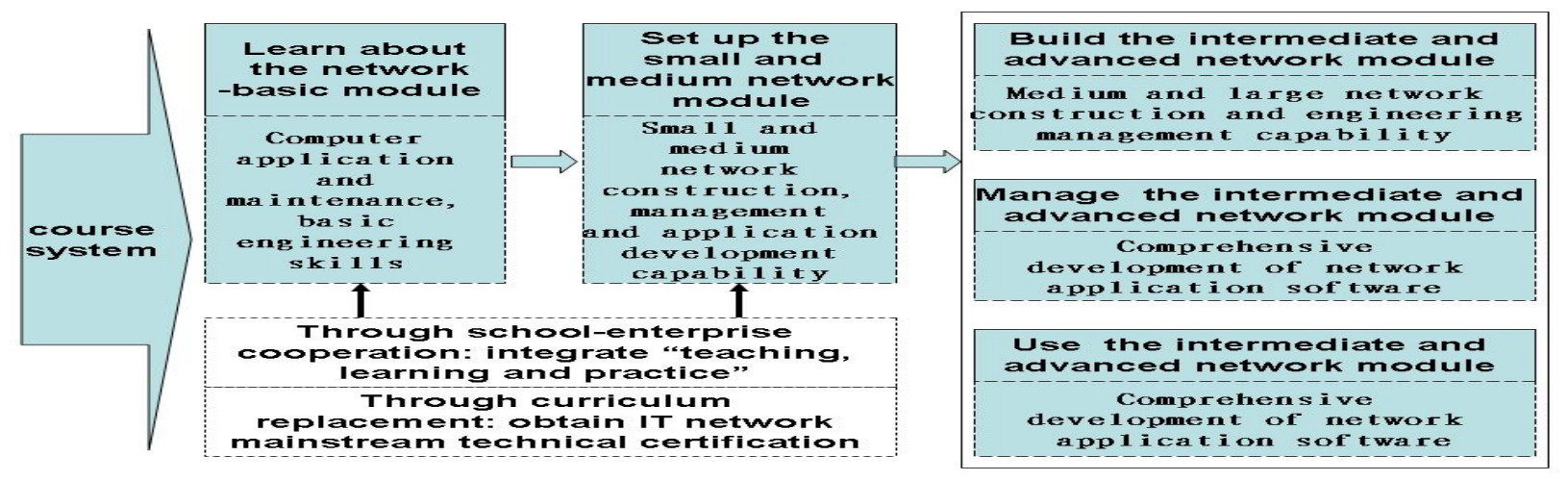

Figure 1. "Modularized, combined and advanced" curriculum system

- In the teaching process, theoretical teaching, practical curriculum training, substituted post exercitation and employment are realized through school-enterprise cooperation. For example, in the cooperation with MAIWEI Information Co., Ltd, the enterprise was required to accredit specialized vocational planners (one for every one hundred students) to manage relevant classes at school, tutor and assess students, and participate in the whole process of teaching and assessment. The enterprise arranged students to have operation as practical curriculum training on the engineering field, which reflects open, vocational and practical teaching, solids the dynamic integration of practical training, simulation training and substituted post exercitation, and energetically expands the cultivation of students' ability in social communication.

- Properly launch enterprise classroom. Reasonably utilize enterprise resources in various fields to launch education in vocational moral qualities, vocational legal awareness and legal norms. Its objective is to help students initially establish basic awareness of vocational morality and legal norms by guiding students to experience corporate culture, understand corporate management and cognize corporate environment, so as to make early preparations for the transition from undergraduates to employees. Enterprise classroom can invite principals or experienced technicians from cooperative enterprises and have face-to-face communication with students about practical working experience via either lectures or classroom instruction.
- Examine and evaluate work-integrated learning. With the purpose of improving teaching quality, the proportion of classroom operation and practical training performance should be increased in accordance with the formulated teaching management and evaluation system. Moreover, work-integrated learning can be integrated with practical training program to verify if students have mastered specific vocational abilities and other capability factors.

- Enterprises should assist vocational colleges in cultivating their faculty and deepen work-integrated talent training construction. Taking Computer Network as the entry point, it is explicitly stipulated in the cooperation agreement with Hunan MAIWEI Technology Co., Ltd. that the enterprise provide relevant teachers with network engineering-related training to help them promote the capability and level of teaching practical projects. As to the aforesaid teachers of relevant majors, if they need to teach school-enterprise cooperation majors, the enterprise should pay for their CNCIW international certification test to assist them obtain relevant teaching qualification.

\section{CONCLUSION}

In summary, work-integrated talent training mode is the intrinsic requirement of vocational education ${ }^{[6]}$. Comprehensively carry out this mode and combine 
students' personalized development with the cultivation of comprehensive qualities, highlight students' professional skills while reinforcing and enhancing their capability of mastering basic knowledge; place emphasis on the capability of applying technology while valuing the one of sustainable development ${ }^{[7]}$. At present, under the environment of incomplete school-enterprise cooperative system, vocational colleges should continuously integrate industrial and enterprise resource, energetically attract enterprises to participate in vocational education and take the initiative to reflect industrial and corporate requirements in the teaching process ${ }^{[8]}$. Furthermore, they should actively and effectively explore and practice in "school-enterprise corporation and work-integrated learning", with the aim to make contributions to constructing higher vocational education with Chinese characteristics.

\section{ACKNOWLEDGMENT}

This research is supported by the 12th five-year plan project in hunan province (No. XJK013BXX006).

\section{REFERENCES}

[1] The State Council: The Decision on Energetically Developing Vocational Education, State Document No. (2005) 35

[2] Hao Jianfeng. Work-integrated Talent Training Mode in Higher Vocational Education. Guangxi Vocational Technical Institute.2010. 12 (3): 31.

[3] Li Yali. Work-integrated Talent Training Mode. China Adult Education.2010.12 (5): 78

[4] Huang Shuai, Song Guoxin, 2006, Hexagon-based Self-adaptive Search Algorithm Using Successive Elimination. Computer Engineering 32(2006) 212-214.

[5] Han Zhigeng, Wang Jian, Research and improvement of the marking block in the PMVFAST algorithm. Computer Engineering\&Science 28(2006) 70-72.

[6] Liu Changjin, Guo Li, Block matching criterion based on DCT coefficients distribution. Mini-Micro Systems 27(2006) 893-895.

[7] Nian Tengfei. "Work-integrated" Talent Training Mode in Vocational Education. Success (education).2010.12 (15): 251

[8] Wei Chang Wong, Chi Chiu Chan, Li Han Chen, Tao Li, Kok Xian Lee, Kam Chew Leong, Polyvinyl alcohol coated photonic crystal optical ber sensor for humidity measurement, Sensors and Actuators B: Chemical, 174 (2012), 563-569. 